\title{
Endodontia regenerativa: avanços na terapia endodôntica
}

\author{
Regenerative Endodontics : advances in endodontic therapy \\ Bansal R, Jain A, Mittal S. Current overview on challenges \\ in regenerative endodontics. Journal of Conservative \\ Dentistry : JCD. 2015;18(1):1-6. doi:10.4103/0972-0707.148861. \\ Cosme-SILVA, L. \\ Mestrando em Ciências Odontológicas- UNIFAL- MG \\ Naiana Viana Viola Nicoli \\ Professora de Endodontia-Universidade Federal de Alfenas
}

Quando se tem necrose de dentes permanentes com rizogênese incompleta o procedimento de apicificação vem sendo indicado. É uma técnica que na maioria das vezes, após o preparo biomecânico dos condutos radiculares se utiliza, na região apical, um material biocompatível, osteoindutor e osteocondutor como o agregado trioxido mineral (MTA). Ele é usado para estimular a formação de tecido duro e, consequentemente fechamento da região periapical. Contudo, apesar de ser uma técnica bastante utilizada, ela não permite o crescimento radicular do dente, o que faz com esse elemento dental fique mais susceptível à fratura.

A endodontia regenerativa traz um procedimento promissor para dentes jovens que estejam necrosados e com ápice aberto. A partir da regeneração conseguida com essa abordagem ocorre a revitalização do dente necrosado, o que permite que crescimento radicular seja continuado dando maior suporte ao dente na cavidade bucal. Para se ter sucesso nessa terapia é preciso que os canais radiculares passem por uma sanificação com substâncias químicas, como hipoclorito de sódio, que é associado a uma medicação intracanal, conhecida como pasta tri-antibiótica, composta por associação de três medicações: ciprofloxacino, metronidazol e moniciclina. A instrumentação deve ser mínima, e um sangramento apical deve ser induzido para que células tronco contidas na região apical possam formar um arcabouço para o processo regenerativo. Após esses procedimentos um material biocompatível deve ser utilizado para vedar o terço coronário.

Mesmo se mostrando uma técnica promissora, alguns desafios continuam sem esclarecimentos. Um deles questiona como as células tronco, encontradas na região apical e responsáveis pela regeneração, sobrevivem a ambientes hostis, como por exemplo, de intensa inflamação apical quando há um abscesso instalado. Outro desafio é a desinfecção dos canais radiculares que é fundamental. Por isso, a pasta tri antibiótica tem sido indicada, porém ela causa um grande manchamento na coroa dentária. Para que isso não ocorra, o uso do sistema EndoVac (irrigação por pressão negativa apical) tem se mostrado efetivo na limpeza dos canais radiculares e também de istmos, o que pode ser um substituto desta associação de medicações.

O protocolo de acompanhamento recomendado pela AAE (Associação Americana de Endodontia), publicado em 2013, mostra que a avaliação radiográfica deve ser realizada em torno de 6-12 meses, onde as radiografias devem mostrar, claramente, ausência de rarefação óssea apical, sugerindo a cura da 
alteração. Aos 12-24 meses um aumento na espessura da parede dentinária também deve estar visível, juntamente com o aumento do comprimento da raiz. Além disso, clinicamente o dente deve estar respondendo positivamente aos testes de frio, sem ausência de sintomatologia dolorosa e exercendo suas funções no aparelho estomatognático

São inúmeros os trabalhos que mostram resultados positivos quando esta abordagem é empregada. Entretanto, a literatura também enfatiza resultados não satisfatórios demos- trando que, mesmo seguindo corretamente os protocolos recomendados, é uma regeneração com resultados imprevisíveis. Sendo assim, é legítimo considerar que a endodontia regenerativa possui um grande potencial na revitalização de dentes imaturos necrosados. Contudo, estudos a longo prazo necessitam ser realizados para que se confirme, de forma mais clara e objetiva, os resultados dessa terapia.

Submetida em: 4-11-2015

Aceita em: 5-11-2015 